\title{
DIMENSÃO SOCIAL DOS INDICADORES DE SUSTENTABILIDADE DOS MUNICÍPIOS PRODUTORES DE PETRÓLEO E GÁS DO RIO GRANDE DO NORTE
}

\section{Ceres Virginia da Costa Dantas}

Diretoria de Educação e Tecnologia de Recursos Naturais - IFRN Campus Natal Central E-mail: ceresdantas1@gmail.com

\section{Leci Martins Menezes Reis}

Diretoria de Educação e Tecnologia de Recursos Naturais - IFRN Campus Natal Central E-mail: leci@cefetrn.br

\section{RESUMO}

Num contexto de busca pelo desenvolvimento sustentável, com participação e envolvimento do governo, das corporações e da sociedade civil, faz-se necessário o uso de instrumentos de mensuração desse desenvolvimento, que explicitem suas dimensões e em que medidas têm havido mudanças. Fazendo uso de uma dessas ferramentas, o objetivo deste trabalho é avaliar o nível de sustentabilidade dos municípios produtores de petróleo e gás do Rio Grande do Norte em sua dimensão social, através dos indicadores de desenvolvimento sustentável determinados na publicação IDS (2008) do IBGE.

PALAVRAS-CHAVE: Desenvolvimento. Petróleo e Gás. Sustentabilidade. Competitividade. Indicadores Sociais. 


\section{DIMENSÃO SOCIAL DOS INDICADORES DE SUSTENTABILIDADE DOS MUNICÍPIOS PRODUTORES DE PETRÓLEO E GÁS DO RIO GRANDE DO NORTE}

\section{INTRODUÇÃO}

A partir de meados da década de 80 , quando se fizeram notar os efeitos da exploração humana no planeta, alterações físico-químicas na natureza, o conceito de desenvolvimento sustentável começou a ser discutido, buscando-se uma nova compreensão da economia mundial e conseqüente mudança de enfoque do crescimento econômico: antes, centrado apenas em questões financeiras, tributárias e de geração de receitas; no novo modelo passa a incorporar as diferenças regionais e sociais e a necessidade de preservação do meioambiente.

Segundo o Relatório da Comissão Mundial de Desenvolvimento e Meio Ambiente das Nações Unidas, o desenvolvimento sustentável é aquele "capaz de suprir as necessidades da população mundial sem comprometer as necessidades das populações futuras" (CMMAD, 1988).

Desse modo, o desenvolvimento sustentável começa a fazer parte do sistema econômico atual, exigindo ferramentas de metodologia de avaliação da problemática ambiental de forma integrada. Surge, daí, a construção dos indicadores de sustentabilidade como uma das possibilidades.

A ideia de desenvolver indicadores de sustentabilidade despontou na Conferência Mundial sobre o Meio Ambiente (Rio-92), conforme registra seu documento final, a Agenda 21. A proposta era definir padrões sustentáveis de desenvolvimento que considerassem aspectos ambientais, econômicos, sociais, éticos e culturais. Os indicadores surgem como ferramentas constituídas por uma ou mais variáveis que, associadas de diversas formas, revelam significados mais amplos sobre os fenômenos a que se referem, além de serem essenciais para guiar a ação e subsidiar o acompanhamento e a avaliação do progresso alcançado rumo ao desenvolvimento sustentável (IBGE, 2004). Sua utilização a partir das devidas adequações e ajustes para contexto e contingências específicas, permite avaliar o nível de sustentabilidade do Brasil, regiões e localidades a partir da existência / intensidade dos indicadores dentro de cada dimensão. Essa mensuração da sustentabilidade está relacionada à utilização de ferramenta que capture a complexidade do desenvolvimento, sem reduzir a significância de cada um dos componentes do sistema (MALHEIROS et al., 2008).

Centrado na sustentabilidade, o presente trabalho dá continuidade aos estudos que têm sido desenvolvidos na linha de pesquisa denominada "Meio Ambiente e Desenvolvimento do Semi-árido" (IFRN/CNPq), que remontam ao período atual da sociedade que vivencia o predomínio da globalização contemporânea, sistema que traz em seus esteios uma lógica destrutiva que tem gerado aparentemente um novo conjunto de problemas políticos e ambientais, um fosso cada vez maior entre os que têm e os que não têm, alterando até nossas percepções sobre o tempo e o espaço (HARVEY, 2004; BAUMAN, 1999). Esta é uma nova fase de um mesmo processo de produção capitalista do espaço ou que é entendida, no âmbito desse estudo, como a etapa superior da espacialidade do capital, e 
que tem se manifestado pelo espraiamento do capital produtivo e financeiro vinculado a grandes corporações de diversos ramos socioeconômicos, sobretudo, em escala global.

Essa é, por exemplo, a situação geográfica de exploração e produção de petróleo e gás desenvolvida pela Empresa Petróleo Brasileiro S/A (Petrobras) que vem se constituindo numa grande corporação do País e, porque não dizer, do mundo. Na história recente de exploração da atividade petrolífera já deixou marcas irreversíveis na paisagem social e ambiental dos territórios onde se desenvolveu.

A exploração do petróleo no Brasil teve início no final dos anos 30, início dos anos 40, com a descoberta de campos onshore no Nordeste. Alguns anos mais tarde, com a descoberta de reservas offshore, o petróleo tornou-se atenção nacional. No Rio Grande do Norte as primeiras pesquisas de petróleo tiveram início em 1943, desenvolvidas pelo Departamento Nacional de Produção Mineral (DNPM). Porém, somente a partir da segunda metade da década de 70 a indústria do petróleo instalou-se definitivamente no semi-árido potiguar (JESIEL, 2007).

A empresa se destaca internacionalmente, com tecnologia própria para águas ultraprofundas; está produzindo petróleo a preços competitivos em campos offshore (marítimos) a profundidades cada vez maiores e em campos onshore (terrestres, como é o caso do Rio Grande do Norte, considerado nessa situação como o maior produtor do País), atraindo o interesse de companhias petrolíferas de todo o mundo, com as quais está assinando acordos de parceria para a exploração e produção de suas reservas na enorme plataforma submarina brasileira.

A indústria do Petróleo é na atualidade um dos mais importantes setores econômicos da sociedade moderna e, de modo particular para o Rio Grande do Norte, tendo em vista que a área da pesquisa é uma das maiores produtoras de óleo e gás natural do território brasileiro. Atualmente no Estado, há aproximadamente três mil poços produzindo petróleo, tanto em terra como em mar, totalizando aproximadamente $11.837 \mathrm{~km}^{2}$, o equivalente a 22,42\% da superfície territorial (BRASIL, 2009).

A abertura da área de exploração e produção (E\&P) para parceiros internacionais gerou, por sua vez, oportunidades em outras partes do mundo, principalmente quando se considera que o know how dessa empresa pode contribuir para a realização de negócios. Porém, o processo de exploração e produção de petróleo e gás tem, de certa maneira, apresentado problemas de ordem sócio-ambiental.

Nesse contexto, o estudo ora proposto tem como objeto de pesquisa a dimensão social dos indicadores de sustentabilidade dos municípios produtores de petróleo e gás do Rio Grande do Norte, num momento em que já há grande multiplicidade de problemas ambientais que afetam a qualidade de vida e o meio ambiente das pessoas: degradação de recursos naturais, proliferação de resíduos sólidos, insalubridade residencial, contaminação de mananciais, de solos e da água, dentre outros. Além disso, pretende-se construir um suporte técnico-analítico para a formulação de estratégias necessárias para a melhoria do meio ambiente local.

A área de exploração e produção encontra-se na porção noroeste do Rio Grande do Norte (também chamada região do Alto-Oeste) nos terrenos sedimentares da Bacia Potiguar. Dessa Bacia fazem parte os municípios de Açu, Alto do Rodrigues, Apodi, Areia Branca, 
Caraúbas, Carnaubais, Felipe Guerra, Governador Dix-sept Rosado, Guamaré, Macau, Mossoró, Pendências, Porto do Mangue, Serra do Mel e Upanema, e também os municípios cearenses de Aracati e Icapuí. Os quinze municípios norte-rio-grandenses compõem o recorte espacial da pesquisa.

Na cidade de Guamaré está o pólo industrial, que beneficia o óleo e o gás natural oriundos dos campos marítimos de Ubarana e Agulha, e dos campos terrestres de todo o Estado. O Campo de Canto do Amaro, entre os municípios de Mossoró e Areia Branca, é um dos maiores produtores de petróleo em terra do Brasil, extraindo 47 mil barris por dia em, aproximadamente, 3,5 mil poços perfurados (JESIEL, 2007). Essa produção corresponde a $50,5 \%$ da produção total do Estado que é, em média, de 93 mil barris/dia. O gráfico 01 expressa a evolução da produção do petróleo no Rio Grande do Norte, desde o ano de 2000.

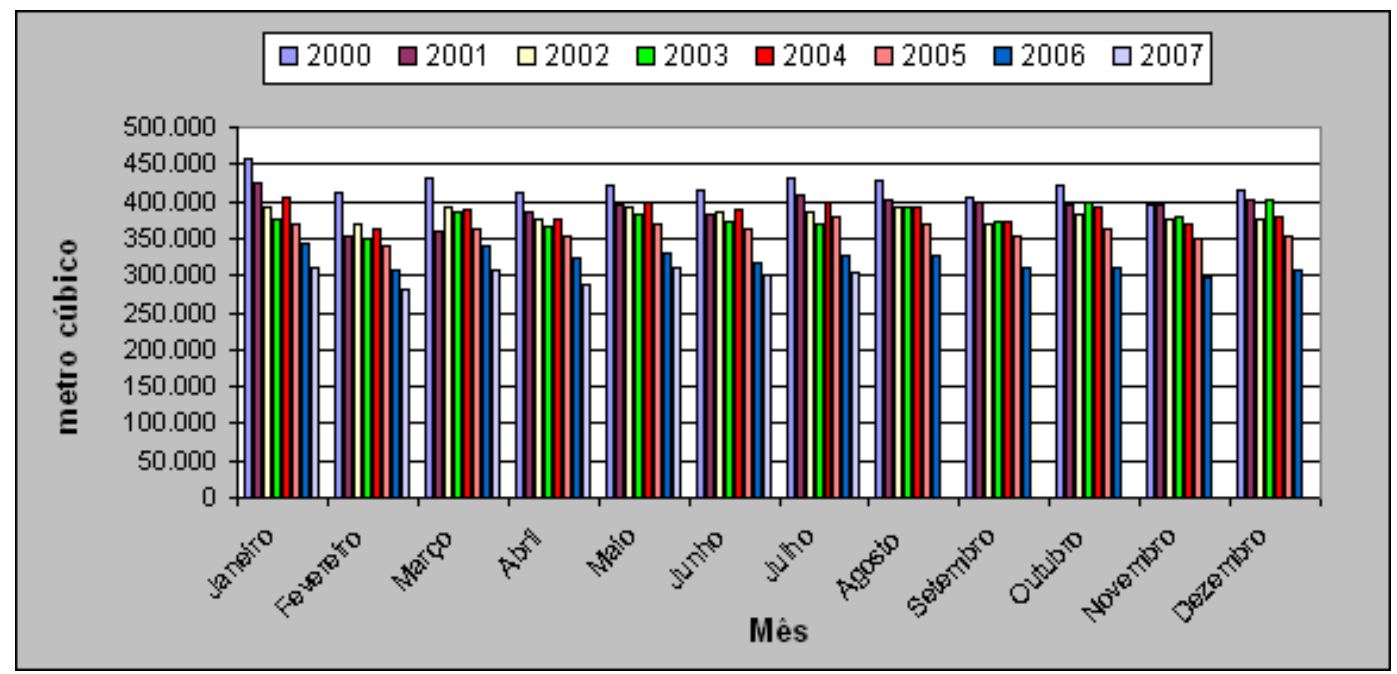

Gráfico 01 - Produção de petróleo no Rio Grande do Norte Fonte: Agência Nacional do Petróleo, 2007.

Para se ter ideia da importância do petróleo para a economia potiguar, e particularmente para a área de estudo, o pagamento de royalties efetuado aos municípios produtores de petróleo no Estado, no ano de 2006, foi de R\$ 113.072.372,40. Isso deu ao Estado o segundo lugar em recebedor de royalties, decorrentes da sua mencionada posição de grande produtor petrolífero.

Os royalties pagos pela Petrobras beneficiam o governo (Estado), os municípios produtores e os não produtores (limítrofes, área de influência), além dos donos de sítios e fazendas que tiveram suas terras perfuradas. O objetivo inicial desses pagamentos é a construção de um fundo de compensação pela alienação de um patrimônio público, ou seja, a preparação sócio-econômica do local cuja economia corrente está baseada no petróleo para o momento do esgotamento desse recurso.

Apesar do dinamismo econômico decorrente da produção de petróleo e dos royalties pagos pela Petrobrás, as áreas rurais desses municípios convivem com diversos problemas de ordem socioambiental, pois os suportes econômicos dessas áreas ainda estão basicamente pautados numa economia decadente, ou melhor, em processo de declínio, como é o caso do complexo gado-algodão-agricultura de subsistência. Além disso, a maior parcela desses 
municípios praticamente sobrevive dos recursos oriundos do Fundo de Participação dos Municípios (FPM) e de assinatura de convênios com os governos estadual e federal.

Tabela 01 - Repasse de royalties da Petrobrás para municípios produtores de petróleo no Rio Grande do Norte (2006)

\begin{tabular}{|c|c|c|c|}
\hline Municípios & $\begin{array}{l}\text { Receita de Roaylties } \\
\text { (valores em R\$) }\end{array}$ & $\begin{array}{c}\text { Despesas de } \\
\text { Investimentos (valores } \\
\text { em } \mathrm{R} \$ \text { ) } \\
\end{array}$ & $\begin{array}{l}\text { Aplicação em } \\
\text { Investimentos } \\
\text { (valores em \%) }\end{array}$ \\
\hline Açu & $3.381 .246,78$ & $2.452 .750,00$ & 72,5 \\
\hline Alto do Rodrigues & $3.861 .633,48$ & $1.285 .716,00$ & 33,3 \\
\hline Apodi & $3.068 .003,39$ & $2.536 .714,00$ & 82,7 \\
\hline Areia Branca & $10.789 .404,56$ & $3.048 .065,00$ & 28,3 \\
\hline Caraúbas & $2.005 .872,16$ & $1.164 .498,00$ & 58,1 \\
\hline Carnaubais & $1.973 .903,55$ & $148.843,00$ & 7,5 \\
\hline Felipe Guerra & $3.561 .519,52$ & $1.639 .874,00$ & 46,0 \\
\hline Gov. Dix-sept Rosado & $3.551 .886,63$ & $2.290 .536,00$ & 64,5 \\
\hline Guamaré & 22.318.391,10 & $9.996 .438,00$ & 44,8 \\
\hline Macau & $22.377 .562,99$ & $4.751 .369,00$ & 21,2 \\
\hline Mossoró & $24.834 .159,54$ & $24.617 .004,00$ & 99,1 \\
\hline Pendência & $3.009 .687,41$ & $2.039 .484,00$ & 67,8 \\
\hline Porto do Mangue & 4.657.637,93 & $778.311,00$ & 16,7 \\
\hline Serra do Mel & $1.680 .534,14$ & $844.706,00$ & 50,3 \\
\hline Upanema & $2.000 .929,22$ & $1.707 .674,00$ & 85,3 \\
\hline TOTAL & 113.072.372,40 & 59.301.982,00 & 52,4 \\
\hline
\end{tabular}

Fonte: Base de pesquisa Royalties do Petróleo da Ucam-campos, 2006.

Aliando-se ao exposto acima, pode-se dizer que a análise da literatura pertinente evidencia que até recentemente os problemas ambientais que afetam o cotidiano da população, no nível domiciliar, seja da área rural ou urbana, têm permanecido praticamente ignorados ou recebem pouca atenção tanto dos ambientalistas quanto dos órgãos públicos, em diversos níveis de atuação. As discussões têm se concentrado, geralmente, em fenômenos globais, como: o efeito estufa, o buraco da camada de ozônio, a desertificação, destruição da floresta amazônica, dentre outros.

É sobre o contexto da dinâmica da produção de petróleo e gás do território Norte-riograndense, permeada por incertezas e contradições, que emergem os questionamentos centrais desse estudo: como se encontram os indicadores de sustentabilidade na dimensão social de municípios da área de produção de petróleo e gás do estado do Rio Grande do Norte?

A metodologia utilizada foi o IDS Brasil (2008) do IBGE, conjunto de indicadores que se encontram divididos em 4 dimensões (social, ambiental, econômica e institucional). No entanto, no presente estudo utilizaram-se somente os indicadores da dimensão social, que 
permitem avaliar o nível de sustentabilidade desse aspecto nas diferentes localidades, a partir da intensidade dos dados existentes.

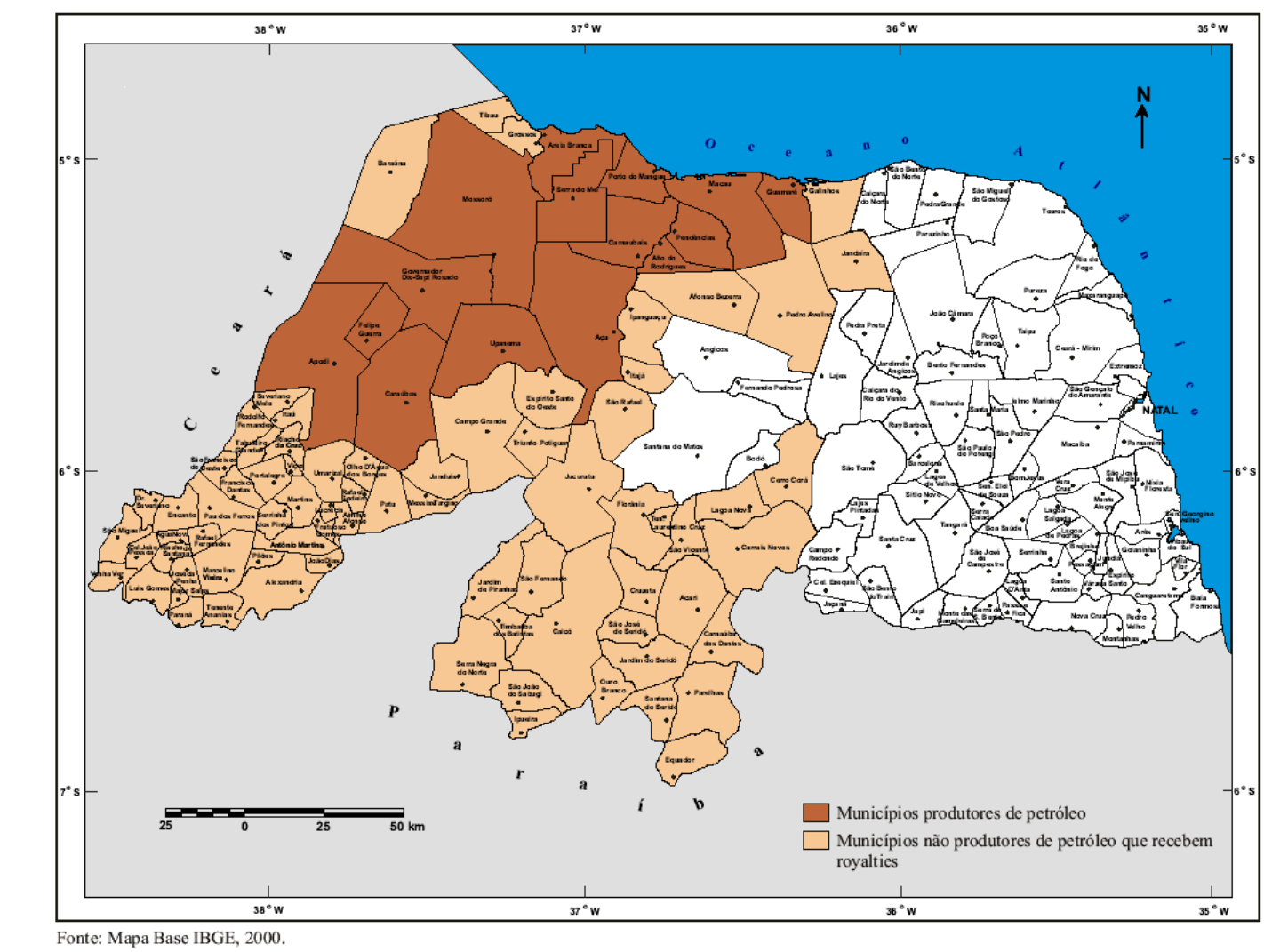

\section{Mapa 01 - Municípios produtores de petróleo no estado do Rio Grande do Norte}

\section{FUNDAMENTAÇÃO TEÓRICA}

Esta seção tem por objetivo expor o universo de princípios, categorias e conceitos sobre indicadores de sustentabilidade a fim de subsidiar os estudos sobre a expansão da produção petrolífera e seus impactos sócio-ambientais em municípios de produção de petróleo e gás do território norte-rio-grandense, para que se possa realizar uma descrição-reflexiva ou uma análise desses indicadores.

A resistência e incompatibilidade evidenciada pela sociedade civil e instituições públicas e privadas em adotar práticas que visem o conciliamento entre as variáveis desenvolvimento e sustentabilidade é resultante de uma série de fatores pertinentes, sendo alguns deles, o sistema capitalista vigente e os conseqüentes avanços tecnológicos, que conduzem a sociedade em geral a adotar práticas que não colaboram com a preservação do meio ambiente. Para tanto, a indisponibilidade dos recursos naturais existentes e a própria degradação do ambiente fez emergir discussões acerca dos princípios da sustentabilidade, no intuito de se obter um vínculo direto entre variáveis até então complexas e distintas.

$\mathrm{Na}$ década de 80, o termo desenvolvimento sustentável surge com maior ênfase e relevância, consagrando-se posteriormente pela Comissão Mundial sobre o Meio Ambiente e Desenvolvimento, denominada como Comissão Brundtland, a qual produziu um relatório considerado básico para a definição desta noção e dos princípios que lhes dão fundamento, 
obtendo uma rápida e ampla repercussão internacional. Tal comissão definiu desenvolvimento sustentável como o desenvolvimento que atende às necessidades do presente sem comprometer a capacidade das futuras gerações atenderem às suas próprias necessidades (CMMAD, 1988).

Como se verifica, a noção de desenvolvimento sustentável tem sua origem mais remota no debate internacional acerca do conceito de desenvolvimento. Trata-se, na verdade, da história da reavaliação da natureza do desenvolvimento predominantemente ligado à idéia de crescimento, até o surgimento do conceito de desenvolvimento sustentável. Essa história esta relacionada a uma nova visão sobre o desenvolvimento. Nesta nova ótica, a noção de desenvolvimento, por muito tempo identificado ao progresso econômico, extrapola o domínio da economia através da sua integração com as dimensões social, ambiental e institucional, apoiando-se em novos paradigmas.

Sachs (2001) mostra que o século XX deixou atrás de si uma prosperidade global sem precedentes, ocasionada por uma má distribuição de recursos e renda (entre as nações e internamente a elas), por problemas sociais e humanitários, pelo histórico de guerras e genocídios e por um sistema internacional incapaz de promover paz duradoura, equidade e desenvolvimento genuíno. O crescimento econômico, se repensado de forma adequada, de modo a minimizar os impactos ambientais negativos e colocado a serviço de objetivos socialmente desejáveis, continua sendo uma condição necessária para o desenvolvimento.

De acordo com Rutherford (1997), o maior desafio do desenvolvimento sustentável é a compatibilização da análise com a síntese. O desafio de construir um desenvolvimento dito sustentável, juntamente com indicadores que mostrem esta tendência, é o de compatibilizar o nível macro com o micro. Para tal autor, as questões relacionadas à sustentabilidade precisam ser analisadas sob diferentes perspectivas e que as principais seriam as relacionadas a aspectos econômicos, ambientais e sociais.

Segundo Leal (2003), a sustentabilidade está relacionada à promoção de um diálogo crítico acerca da ciência e das estratégias tecnológicas para oferecer viabilidade a sistemas produtivos. A atenção na sustentabilidade das organizações surge como uma proposta regular às estruturas burocráticas, definindo padrões ambientais internacionais.

Como decorrência do surgimento e aplicação dos conceitos de desenvolvimento sustentável surge a necessidade de mecanismos que possibilitem a avaliação do processo de aplicação dos seus princípios. Neste contexto, surgem as metodologias de indicadores de sustentabilidade, as quais utilizam um conjunto de dimensões e variáveis específicas explicitadas através de dados quantitativos que permitem estabelecer um cenário sobre o nível de sustentabilidade de espaços geográficos em termos políticos, econômicos, sociais, ambientais, institucionais etc.

\section{Maneiras de aplicação dos Indicadores de Sustentabilidade}

Um dos desafios da construção do desenvolvimento sustentável é o de criar instrumentos de mensuração, tais como indicadores de desenvolvimento. Indicadores são ferramentas constituídas por uma ou mais variáveis que, associadas através de diversas formas, revelam significados mais amplos sobre os fenômenos a que se referem, além de serem essenciais para guiar a ação e subsidiar o acompanhamento e a avaliação do progresso alcançado rumo ao desenvolvimento sustentável (IBGE, 2004). 
A construção de indicadores de sustentabilidade é complexa, porque devem refletir a relação da sociedade com o meio ambiente numa perspectiva ampla, considerando os múltiplos fatores envolvidos no processo. Adotar uma postura sistêmica diante desse problema é necessário para que se possa compreender a realidade dos fatos, uma vez que elementos formadores têm mútua influência.

Os indicadores de sustentabilidade diferenciam-se dos demais por exigirem uma visão de mundo integrada, necessitando relacionar para tanto, a economia, o meio ambiente e a sociedade de uma dada comunidade. Sabe-se que um bom indicador alerta sobre os problemas antes que eles se tornem graves indicando o que precisa ser feito para resolvêlos. É dessa maneira que em comunidades em crise os indicadores são considerados importantes instrumentos para definir soluções e propor um futuro melhor (MARANGON, 2004).

Para Bellen (2005), o próprio processo de desenvolvimento de indicadores de sustentabilidade deve contribuir para uma melhor compreensão do que seja exatamente desenvolvimento sustentável. Os processos de desenvolvimento e avaliação são paralelos e complementares.

No Brasil, o IBGE (Instituto Brasileiro de Geografia e Estatística) desenvolveu um sistema de indicadores: IDS Brasil 2008 (Indicadores de Desenvolvimento Sustentável: Brasil 2008), o qual foi escolhido para execução desse estudo por envolver de forma mais simétrica as dimensões e variáveis exploradas.

Para a realização deste estudo, as perspectivas e indicadores utilizados foram os da dimensão social, que abrange as perspectivas População, Equidade, Saúde, Educação, Habitação e Segurança, bem como os respectivos indicadores - Taxa de crescimento da população, Concentração de renda (índice de Gini), Renda familiar per capita, Rendimento Médio mensal por sexo, Rendimento médio mensal por cor ou raça, Esperança de vida ao nascer, Taxa de mortalidade infantil, Imunização contra doenças infecciosas infantis, Taxa de analfabetismo funcional por cor ou raça, Densidade inadequada de moradores por dormitório e Coeficiente de mortalidade por homicídios.

Os indicadores apresentados cumprem muitas funções e reportam-se a fenômenos de curto, médio e longo prazos, servindo para identificar variações, comportamentos, processos e tendências, e estabelecer comparações entre regiões e municípios dentro do Brasil, além de indicar necessidades e prioridades para a formulação, monitoramento e avaliação de políticas (IBGE, 2008).

A partir de uma breve contextualização acerca do desenvolvimento sustentável e das formas de aplicação dos indicadores de sustentabilidade, verifica-se a real importância em se abordar essa temática na atualidade, bem como a necessidade em se dispor de ferramentas que visam subsidiar o processo de mensuração dos indicadores que o compõem, retratando assim, uma dada realidade.

\section{METODOLOGIA}

A pesquisa classifica-se como descritiva em que, segundo Rudio (1986), “o pesquisador procura conhecer e interpretar a realidade, sem nela interferir para modificá-la”. A 
metodologia utilizada no trabalho foi a pesquisa bibliográfica, análise documental e observação não participante.

Os dados estatísticos que compõem os 14 indicadores utilizados foram coletados no IBGE, no IDEMA, no Atlas de Desenvolvimento Humano do Brasil e no SUS, referindo-se aos 15 municípios que compõem o recorte da pesquisa. Para facilitar a visualização do resultado, foi calculada a média aritmética dos dados encontrados. São apresentados também dados do Estado do Rio Grande do Norte e do país a título de comparação dos resultados.

\section{APRESENTAÇÃO DOS RESULTADOS}

Os resultados obtidos com a realização da pesquisa apontam o nível de sustentabilidade no contexto social das localidades em estudo, baseado no IDS 2008.

Os indicadores da dimensão social correspondem aos objetivos ligados à satisfação das necessidades humanas, melhoria da qualidade de vida e justiça social. Os dados são expostos no Quadro 1.

\section{Perspectiva População}

A taxa média de crescimento da população (entre os anos de 1991 - 2000) na região estudada foi de 1,35; sendo um valor inferior, no entanto próximo aos encontrados para o Estado e para o país. Essa é uma taxa considerável, podendo significar pouca existência de êxodo rural, devido à atividade petrolífera inclusive.

A taxa de fecundidade média foi de 2,64 filhos por mulher, taxa superior ao valor encontrado para o Rio Grande do Norte e para o Brasil, e demonstra que ainda há pouca preocupação com o planejamento familiar na região estudada.

O indicador população e terras indígenas não é relevante para os locais estudados ou para o Estado do RN, já que não há ocorrência de comunidades indígenas na região.

\section{Perspectiva Trabalho e Rendimento}

O índice de Gini - indicador que determina o grau de concentração de renda na população, expresso por um valor que varia de 0 (zero) a 1 (um), sendo o 0 a situação de perfeita igualdade - encontrado para a região em estudo foi de 0,54 , valor muito próximo ao nacional $(0,57)$ mas que demonstra a existência de elevado grau de concentração de riqueza nos municípios em estudo, fato cuja existência recebe contribuição da indústria petrolífera instalada. Seria interessante a implementação de políticas e ações de desenvolvimento de outras atividades econômicas, equalizando ou aproximando a distribuição de riquezas.

O indicador Rendimento Familiar per capita demonstra que em quase metade da população residente nos municípios estudados $(48,09 \%)$ a renda é menor que um salário mínimo. A situação apresenta-se melhor do que a média nacional, mas pior do que a estadual, demonstrando grande diferença na distribuição de renda local. 


\section{Quadro 01: Indicadores Sociais}

\begin{tabular}{|c|c|c|c|c|}
\hline Perspectivas & Indicadores & $\begin{array}{l}\text { Municípios } \\
\text { (médias) }\end{array}$ & $\begin{array}{l}\text { Estado } \\
\text { (RN) }\end{array}$ & Brasil \\
\hline \multirow{3}{*}{ População } & Taxa de crescimento da população & 1,35 & 1,58 & 1,64 \\
\hline & Taxa de fecundidade & 2,64 & 2,5 & 2,38 \\
\hline & População e terras indígenas & 0 & 0 & \\
\hline \multirow{6}{*}{$\begin{array}{l}\text { Trabalho e } \\
\text { Rendimento }\end{array}$} & Índice de Gini (distribuição de rendimento) & 0,54 & 0,7 & 0,57 \\
\hline & Rendimento familiar per capita & & & \\
\hline & Até $1 \mathrm{~S} . \mathrm{M}$. & 48,09 & 38,42 & 57,7 \\
\hline & Até 2 S.M. & 20,53 & 20,19 & 19,1 \\
\hline & Mais de 2 S. M. & 16,96 & 27,86 & 17,4 \\
\hline & Sem Rendimento & 13,8 & 13,53 & 3,8 \\
\hline \multirow{9}{*}{ Saúde } & Esperança de vida ao nascer & 65,26 & 66,1 & 70,4 \\
\hline & Taxa de mortalidade infantil & 50,42 & 48,7 & 30,1 \\
\hline & Imunização contra doenças infecciosas infantis & & & \\
\hline & Contra Pólio & 91,6 & - & 100 \\
\hline & Tetravalente & 86,34 & - & 97 \\
\hline & BCG & 100,72 & - & 100 \\
\hline & Oferta de serviços básicos de saúde & & & \\
\hline & Estabelecimentos de Saúde & 14,57 & 1639 & 77004 \\
\hline & Leitos Disponíveis & 100,00 & 7189 & 443210 \\
\hline \multirow{8}{*}{ Educação } & Taxa de alfabetização & & & \\
\hline & (15 anos ou mais) & 66,00 & 80,4 & 90 \\
\hline & Taxa de escolarização (\%) & & & \\
\hline & Ensino fundamental (7 a 14 anos) & 137,43 & 98 & 96,5 \\
\hline & Ensino médio (15 a 17 anos) & 57,16 & 70,1 & 81,1 \\
\hline & Taxa de analfabetismo funcional por cor & & & \\
\hline & Brancos & - & 37,7 & 6,1 \\
\hline & Negros & - & 51,08 & 14,1 \\
\hline \multirow{2}{*}{ Habitação } & $\%$ de pessoas que vivem em & & & \\
\hline & domicílio com densidade $>2$ por dormitório & 17,21 & 19,98 & 18,7 \\
\hline Segurança & Coeficiente de mortalidade por homicídios (por 100000 hab.) & - & 13,5 & 26,1 \\
\hline
\end{tabular}

Fonte: Dados da Pesquisa (2009).

\section{Perspectiva Saúde}

Os dados da Esperança de Vida ao Nascer encontrados para a região em estudo mostraram-se inferiores aos dados da esperança de vida estadual e da nacional, estipulando que a idade média máxima dos indivíduos no local é de 65,26 anos, e demonstrando possível precariedade nos serviços de saúde. Faz-se necessária a adoção de medidas de melhoria nas condições ambientais, sanitárias e de saúde.

A taxa de mortalidade infantil dos municípios produtores de petróleo e gás do $\mathrm{RN}$ foi de 50,42 mortes para cada 1000 nascidos vivos, valor 67\% maior do que a média nacional $(30,1)$ e muito próximo ao encontrado para o Estado $(48,7)$. É um valor alto e alarmante, expressando a necessidade de medidas de melhorias na saúde, especialmente as relacionadas ao atendimento de pré-natal e seus acompanhamentos, bem como partos e vacinas para recém-nascidos. 
Para os dados da vacinação contra doenças infecciosas infantis foram encontrados resultados satisfatórios para a aplicação da vacina BCG, cuja quantidade de crianças vacinadas foi superior à esperada na campanha. Já para as vacinas contra pólio e, principalmente, a tetravalente (antiga tríplice) a campanha não conseguiu atingir todo o público-alvo, ficando abaixo da percentagem de vacinados a nível nacional. Desse modo, é importante manter as políticas de prevenção às doenças infecciosas e programas de conscientização da população, buscando reduzir cada vez mais a mortalidade infantil local.

Os resultados encontrados para a oferta básica de serviços de saúde mostram uma média de 14,57 estabelecimentos de saúde e 100 leitos por cidade do estudo, valor satisfatório para as médias e pequenas cidades, mas não para as maiores. No entanto, nota-se a existência de grande disparidade entre os municípios em estudo, de forma que a média não é representativa para esse indicador: enquanto na cidade de Mossoró há 1048 leitos, em Felipe Guerra há 12, por exemplo, sendo esses valores proporcionais à quantidade de habitantes.

\section{Perspectiva Educação}

A taxa de alfabetização de adultos encontrada para os municípios em estudo foi de $66,0 \%$, valor $26,7 \%$ menor do que o valor nacional e $17,9 \%$ menor do que a média estadual, dado alarmante que demonstra uma quantidade muito pequena de pessoas com capacidade de ler e escrever. Faz-se necessária de forma urgente a implementação de programas de educação e de alfabetização para a população.

O indicador taxa de escolarização demonstra que, no nível fundamental, a quantidade de alunos inscritos é superior à esperada, significando demanda de adultos a esse nível de ensino, enquanto que a taxa de escolarização no nível médio é consideravelmente inferior. Tal fato pode implicar em baixa capacitação de adultos para ingresso no mercado de trabalho.

Não foram encontrados dados para a taxa de analfabetismo funcional por cor ou raça dos municípios em estudo. Mas os valores para o Estado demonstram grande quantidade de pessoas analfabetas e disparidade entre negros e brancos, com maior quantidade de negros analfabetos. Além disso, o valor é bem maior do que o nacional, sendo recomendados programas de alfabetização da população.

\section{Perspectiva Habitação}

O dado da porcentagem de pessoas que vivem em domicílios com mais de duas pessoas por dormitório para os municípios em estudo $(17,21 \%)$ foi bastante próximo da média estadual (19,98\%) e da média nacional (18,7\%), mas que ainda é considerado um valor alto, fazendo-se necessária a revisão das políticas habitacionais tanto locais quanto de todo o país, tendo em vista a melhor qualidade de vida da população.

\section{Perspectiva Segurança}

Quanto à segurança, o indicador coeficiente de mortalidade por homicídios demonstra que a quantidade no Estado é razoavelmente baixa, havendo relativa segurança pública (média de 13,5 mortes por homicídios de um total de 100000 mortes), valor inferior ao encontrado para o Brasil, que foi de 26,1. Conclui-se que, para os municípios em estudo, esse valor também deve ser baixo, levando em consideração que são, em sua maioria, cidades pequenas. No entanto, como o objetivo ideal é tornar esse valor igual a zero, é importante investir em segurança pública. 
A partir da análise dos indicadores, observou-se que os municípios em estudo apresentaram resultados, em sua grande maioria, negativos, inclusive quando comparados ao valor nacional. Desse modo, fica claro que existem poucas medidas voltadas para a reversão do atual quadro, referente a um aspecto tão importante, que é a qualidade de vida e a equidade social da população.

\section{CONCLUSÃO}

A preservação do ambiente em que vivemos, com o uso consciente dos recursos só poderá ser alcançada quando toda a sociedade se mobilizar nesse sentido. E, enquanto 0 desenvolvimento sustentável não for atingido em sua plenitude, pode-se inferir o nível de sustentabilidade das localidades através dos indicadores estipulados pela Agenda 21 e, no Brasil, pelo IBGE.

Sabe-se que a atividade de extração e refino do petróleo é muito impactante, mas, se bem gerida, pode reduzir os impactos ambientais e trazer muitas benfeitorias para o local de sua instalação, como econômicas, sociais e institucionais.

A presença da Petrobrás no semi-árido do Rio Grande do Norte é muito marcante e destaca-se do contexto das outras atividades econômicas existentes, que se baseia especialmente na agropecuária. Desse modo, esperava-se que a existência dessa atividade no local contribuísse para redução das diferenças sociais existentes atualmente, pela adoção de programas sociais.

No entanto, a análise da dimensão social dos indicadores de sustentabilidade mostrou que os municípios ainda apresentam situação precária em aspectos básicos de infra-estrutura, como educação e saúde, apesar da quantidade de royalties recebidos.

Diante de tais considerações, faz-se necessária a adoção de programas que promovam a melhoria da qualidade de vida dessas populações, como investimentos na saúde, educação e segurança pública, e como conseqüência direta, a promoção da equidade social.

\section{REFERÊNCIAS BIBLIOGRÁFICAS}

BAUMAN, Zygmunt. Globalização: as conseqüências humanas. Rio de Janeiro: Jorge Zahar, 1999.

BELLEN, H. M. V. Indicadores de Sustentabilidade: uma análise comparativa. Rio de Janeiro: Editora FGV. 2005.

CMMAD - COMISSÃO MUNDIAL SOBRE MEIO AMBIENTE E DESENVOLVIMENTO. Nosso Futuro Comum. Rio de Janeiro: Fundação Getúlio Vargas, 1998.

HARVEY, David. Espaços de esperança.São Paulo: Edições Loyola, 2004.

Instituto De Desenvolvimento Sustentável E MEIO AMBIEnTE. Perfil do RN.

Disponível

em 
<http://www.idema.rn.gov.br/contentproducao/aplicacao/idema/socio_economicos/gerados /perfil_rn_2002.asp>. Acesso em 16/11/2009.

INSTITUTO DE DESENVOLVIMENTO SUSTENTÁVEL E MEIO AMBIENTE. Perfil do município. Disponível em <http://www.idema.rn.gov.br/contentproducao/aplicacao/idema/socio_economicos/enviado s/perfil_municipio.asp $>$. Acesso em 16/11/2009.

INSTITUTO BRASILEIRO DE GEOGRAFIA E ESTATISTICA. Censo demográfico, Rio de Janeiro: IBGE, 2000

Indicadores de Desenvolvimento Sustentável: Brasil 2008 (IDS 2008). IBGE: Rio de Janeiro, 2008. p. 389. I CD-ROM: il.. gráfs.. mapas color. (Estudos e pesquisas. Informação geográfica: n, 4) I

JESIEL, Mário. O papel do petróleo no (des) envolvimento dos municípios do semi-árido potiguar. In: PIQUET, Rosélia; SERRA, Rodrigo (Orgs.). Petróleo e região no Brasil. Rio de Janeiro: Garamond, 2007.

LEAL, M. E. L R. Las ciencias administrativas y la sustentabilidade. In: I Foro Nacional sobre La Incorporación de la Perspectiva Ambiental en la Formación Técnica y Professional. San Luise Postosi - México. p. 01-10, 2003.

MALHEIROS, T. F.; PHILIPPI JR, A; COUTINHO, S. M. V. Agenda 21 Nacional e Indicadores de Desenvolvimento Sustentável: contexto brasileiro. Saúde Soc. São Paulo, v.17, n.1, p.7-20, 2008

MARANGON, M., PRESZNHUK, R., SORDI, R.F., AGUDELO, L.P.P., Indicadores de Sustentabilidade como Instrumento para Avaliação de Comunidades em Crise: Aplicação à comunidade de Serra Negra, Revista Educação e Tecnologia Periódico Técnico Científico dos Programas de Pós-Graduação em Tecnologia dos CEFETs-PR/MG/RJ, volume 8, setembro de 2004.

RUDIO, F. V. Introdução ao projeto de pesquisa científica. Petrópolis: Vozes, 1986.

SACHS, Ignacy. Caminhos para o desenvolvimento sustentável. Rio de Janeiro: Garamond, 2000.

SACK, Robert David. Human territorility: it's teory and history. Cambridge: Cambridge University, 1986.

\section{AGRADECIMENTO}

Agradecemos à ajuda financeira do CNPq, sem a qual a realização desse trabalho não seria possível. 